\title{
Fizyolojik stres ve eksojen poliaminlerin Isatis tinctoria L. yapraklarındaki indigo miktarı ve fide gelişimi üzerine etkisi
}

\author{
Effects of physiological stress and exogenous poliamines on seedling growth and \\ indigo amounts in Isatis tinctoria L. leaves
}

\section{Nazan ÇÖMLEKCIOOĞLU, Semra ARIKAN}

Kahramanmaraş Sütçü İmam Üniversitesi, Fen-Edebiyat Fakültesi, Biyoloji Bölümü, 46100, Kahramanmaraş, Türkiye

Sorumlu yazar (Corresponding author): N. Çömlekcioğlu, e-posta (e-mail): noktem80@gmail.com

\section{MAKALE BİLGİSİ}

Alınış tarihi 22 Şubat 2017

Düzeltilme tarihi 19 Ekim 2017

Kabul tarihi 19 Ekim 2017

\section{Anahtar Kelimeler:}

Isatis tinctoria

İndigo

Poliaminler

Kuraklık stresi

Tuz stresi

\begin{abstract}
ÖZ
Bu çalışmada kontrollü koşullarda büyütülen I. tinctoria (çivitotu) bitkisinin çevresel stres koșullarına toleransı ve dıșsal poliaminlere tepkisi araștırılmıştır. İlk aşamada bitkiler dört farklı tuz derişimindeki $(0,50,100$ ve $200 \mathrm{mM}) \mathrm{NaCl}$ solüsyonu ile sulanarak tuz stresine maruz bırakılmıştır. Bitkiler genelde artan tuz dozlarını tolere ederken, $200 \mathrm{mM}$ 'lık tuz konsantrasyonundan etkilenmiş ve indigo da dahil olmak üzere verim düşmüştür. İkinci aşama olarak fideler kuraklık stresine maruz bırakılmış ve 3., 7. ve 10. günde kuraklığın etkileri incelenmiștir. Kuraklıkta geçen gün sayısı arttıkça indigo ve verimde azalma olmuş, en düşük değerler 10. gündeki verilerden elde edilmiştir. Üçüncü aşama olan poliamin uygulamasında spermin, spermidin ve putresin poliaminleri dört farklı konsantrasyonda $(0,0.1,1$ ve $2 \mathrm{mM})$ yapraktan uygulanmıștır. Uygulamada tüm poliaminler indigo ve fide verimini artırmış, en iyi sonuç putresinden elde edilmiştir. Dördüncü aşama olan poliamin+tuz stresi uygulamalarında indigo miktarını ve yaprak verimini en çok artıran ve etkili olan poliamin putresin olmuştur. Beşinci aşama olan poliamin+kuraklık stresi uygulamasında spermin başta olmak üzere tüm poliaminlerin etkili olduğu görülmüştür.
\end{abstract}

\section{ARTICLE INFO}

Received 22 February 2017

Received in revised form 19 October 2017

Accepted 19 October 2017

\section{Keywords:}

Isatis tinctoria

Indigo

Polyamines

Drought stress

Salinity stress

\begin{abstract}
In this study, I. tinctoria (woad) cultivated under controlled conditions was investigated for its tolerance to environmental stress conditions and its response to external polyamines. The plants were exposed to salinity stress by irrigating the soil with four different concentrations $(0,50,100$ and $200 \mathrm{mM})$ of $\mathrm{NaCl}$ solution While plants generally tolerated increasing salt doses, they were affected by a salt concentration of $200 \mathrm{mM}$ and the yield, including indigo, decreased. As a second step, seedlings were exposed to drought stress and the effects of drought on the $3^{\text {rd }}, 7^{\text {th }}$ and $10^{\text {th }}$ days were examined. While the number of days in the drought increased, the indigo and yield decreased, and the lowest values were obtained at $10^{\text {th }}$ day. In the third step, spermine, spermidine and putresin polyamines were applied at four different concentrations $(0,0.1,1$ and $2 \mathrm{mM})$ on the leaves of plant. In practice, all polyamines increased the yield of indigo and seedlings, however the best results were obtained from putresin. The fourth stage was polyamine + salt stress application and in this stage, putresin was the most effective polyamine which increased the amount of indigo and leaf yield. Polyamine + drought stress was the fifth stage, and all polyamines, especially spermine, were found to be effective in this stage.
\end{abstract}

\section{Giriş}

Sentetik boyalar tekstil sektöründe yoğun bir șekilde kullanılmasına rağmen ekolojik ve zararsız olmasından dolayı doğal boyarmaddelere artan bir ilgi vardır (Gilbert and Cook 2004). Doğal boyarmaddelerin en önemli kaynağını oluşturan bazı boya bitkilerinin tekrar yetiştiriciliğinin yapılması, doğal boyamacılığın yeniden gelişmesine önemli katkıda bulunacaktır (Gönüz ve ark. 2006). Anadolu'da çivitotu olarak da isimlendirilen ve mavi rengin kaynağı olarak bilinen I. tinctoria
L. (Brassicaceae), Güneydoğu Asya'ya özgü olup Avrupa, Asya ve Kuzey Afrika genelinde yaygındır. Tarih öncesi çağlardan beri insanlı̆̆ın en önemli mavi boya maddesi olan indigo elde etmek için Akdeniz ülkelerinde yüzyıllar boyunca çivitotu yetiştirilmiştir (Verzera ve ark. 2010). İndigo bitkide sekonder metabolizma ürünü olup, I. tinctoria bitkisinin ilk yıl oluşan yapraklarından elde edilen boya doğada parçalanma özelliğine 
sahiptir ve çevreye zarar vermeden tehlikesizce kullanılabilir (Özel 2007).

Bitki gelişimi uygun çevresel koşullar altında normal seyrinde gerçekleşirken, stres faktörleri bitkinin gelişimini olumsuz yönde değiştirerek bitkilere negatif etki yapmaktadır (Binici 2005). Tuzluluk stresi, bitki çevresinde meydana gelen önemli seviyedeki su azalması ile ortaya çıkarken, düşük yağmur yağışı ile beraber gelen bir sorun olarak karşımıza çıkmaktadır (Battal ve ark. 2007). Topraklardaki tuzluluk, bitkinin dışında bir ozmotik potansiyel meydana getirerek su almasını engellemekte, ayrıca $\mathrm{Na}^{+}$ve $\mathrm{Cl}^{-}$iyonları toksik etkiye neden olabilmektedir (Khajeh-Hosseini ve ark. 2003). Her iki stres altında da su alımında azalma ve aşırı iyon alımı söz konusudur (Kaya ve ark. 2006). Büyümeyi teşvik eden, hücre bölünmesi, DNA replikasyonu ve hücre farklılaşması gibi düzenleyici işlemlerde geniş rol oynayan poliaminler, çok yıllık bitkilerde tuz stresi de dahil çeşitli abiyotik streslerle karşılaştıklarında artış gösterir (Mutlu ve Bozcuk 2013). Buna bağlı olarak poliaminlerin bitkiye dişarıdan uygulanması sonucunda çeşitli bitkilerin abiyotik streslere karşı toleransının arttığı gözlenmiştir (Kreczmer ve ark. 2013).

$\mathrm{Bu}$ çalışmada indigo kaynağı I. tinctoria kontrollü şartlar altında yetiştirilmiş ve çeşitli stres faktörlerine tabi tutulmuştur. Bitkiye hormon, stres ve hormon-stres uygulaması yapılarak bitkinin indigo üretim miktarı ölçülmüştür. Çalışmada poliaminlerden putresin, spermin ve spermidinin farklı konsantrasyonları uygulanarak, indigo üretimi için en uygun hormon ve konsantrasyon belirlenmeye çalış1lmıştır.

\section{Materyal ve Yöntem}

\subsection{Bitki Materyali ve Büyüme Koşullart}

Bu çalışmada materyal olarak kullanılan, I. tinctoria'ya ait tohumlar, kültür bitkisi olup, KSÜ Fen-Edebiyat Fakültesi Biyoloji Bölümü'nden temin edilmiştir. I. tinctoria tohumları 2:1 oranında torf:perlit karışımı harç bulunan hacmi 2 lt'lik saksılarda, $25 \pm 1{ }^{\circ} \mathrm{C}, 16 / 8\left(55 \mu \mathrm{mol}\right.$ foton $\mathrm{m}^{-2} 1$ şı $\left.\mathrm{k}^{-1}\right)$ 1şı $\mathrm{k} /$ karanlık fotoperiyodunda ve $\% 65$ nem içeren iklimlendirme odas1 standart koşullarında yetiştirilmiştir. Her uygulama için 10'ar saksı kullanılmıştır. Tohumların çimlenmesinden sonra fideler 8-10 tam gerçek yaprağa sahip olduklarında stres ve hormon uygulamalarına başlanmıştır (Binici 2005).

\subsection{Stres Uygulamalart}

Tuz stresi: 0, 50, 100 ve $200 \mathrm{mM}$ konsantrasyonlarındaki $\mathrm{NaCl}$ solüsyonuyla iki hafta boyunca her gün $10 \mathrm{ml}$ sulanmak suretiyle bitkiler tuz stresine maruz bırakılmışlardır (Hediye 2009; Ayyıldız 2011). Kuraklık stresi: stres grubundaki bitkiler sulanmayarak uygulanmıștır. Kuraklık stresine bağlı olarak yapraklardaki indigo değişiminin belirlenmesi için, uygulamanın 3., 7. ve 10 . günlerinde saat 10.00 'da bitkiler hasat edilmiştir (Uzunlu 2006; Aksoy 2008). Her iki uygulama da kontrol grubundaki bitkiler saf su ile sulanmıştır.

\subsection{Poliamin Uygulaması}

$0 \mathrm{mM}$ (kontrol), $0.1 \mathrm{mM}, \quad 1 \mathrm{mM}$ ve $2 \mathrm{mM}$ konsantrasyonlarında hazırlanan poliamin solüsyonları, bitki yapraklarına spreyleme yöntemiyle bir hafta ara ile $4 \mathrm{kez}$ püskürtülmüştür. Kontrol grubundaki bitki yaprakları ise distile su ile spreylenmiştir (Ali ve ark. 2007; Korkmaz 2008).

\subsection{Poliamin+Stres Uygulamalart}

Poliamin+Tuz stresi uygulamas1: Spreyleme yöntemi ile poliamin uygulandıktan sonra bitkiler 2 hafta boyunca her gün $10 \mathrm{ml} 200 \mathrm{mM} \mathrm{NaCl}$ solüsyonuyla sulanmıştır (Ali ve ark. 2007; Saleethong ve ark. 2013). Poliamin+Kuraklık stresi uygulamas1: Poliamin uygulamasından sonra 10 gün su verilmeyerek bitkiler kuraklık stresine maruz bırakılmıştır. Poliamin uygulaması yapılan kontrol bitkileri her iki stres grubunda da saf suyla muamele görmüştür (Ali ve ark. 2007; Farooq ve ark. 2009).

\subsection{Morfolojik Ölçümler}

Her uygulama grubundaki bitkilerin, yaprak ve kök kısımları birbirinden ayrılmış ve yaş ağırlıkları tartılmıştır. Daha sonra etüvde 48 saat $100{ }^{\circ} \mathrm{C}$ 'de kurutulduktan sonra tekrar tartılarak kuru ağırlıkları bulunmuştur. OSİ= [(YA-KA) / YA] x 100 formülüne göre hesaplama yapılmıştır (OSİ: Oransal $\mathrm{Su}$ İçeriği, YA: Yaş Ağırlık, KA: Kuru Ağırlık) (Korkmaz 2008).

\subsection{Indigo miktarının spektrofotometrik analizi}

10 farklı bitkinin yapraklarından $1 \mathrm{~cm}^{2}$ lik diskler alınmış ve toplamda $1 \mathrm{~g}$ taze yaprak cam tüplere bırakılmış ve üzerine $10 \mathrm{ml}$ saf su eklenmiştir. Kaynar haldeki su banyosunda $10 \mathrm{dk}$ bekletildikten sonra buz yardımıyla hızlıca soğutulmuştur. Diskler çıkarıldıktan sonra, konsantre $\mathrm{Ca}(\mathrm{OH})_{2}$ ile pH's1 11 'e ayarlanmıştır. 1 saat oda sicaklığında bekletildikten sonra, konsantre $\mathrm{HCl}$ asit ile $\mathrm{pH}$ 's1 1-2'ye ayarlanmıştır. $10 \mathrm{dk}$ bekletildikten sonra $1 \mathrm{ml}$ 'lik kısım $5 \mathrm{ml}$ etil asetat ile ekstrakte edilmiştir. $\mathrm{Bu}$ ekstrakt spektrofotometrede $600 \mathrm{~nm}$ 'de okunmuştur (Gilbert ve ark. 2004; Comlekcioglu ve ark. 2015).

\subsection{Verilerin İstatiksel Analizi}

Üç tekerrürlü olarak ayrı ayrı kurulan stres, hormon, streshormon denemelerinin istatistiksel analizi, tam şansa bağlı (tesadüf parselleri) deneme desenine göre tek yönlü varyans analizi ile değerlendirilmiştir. Varyans analizinde önemli bulunan özelliklerine ait ortalamaların karşılaştırılmasında Duncan çoklu karşılaştırma testi kullanılmıştır (Bek ve Efe 1995).

\section{Bulgular ve Tartışma}

\subsection{Tuz Stresi Uygulaması Sonuçları}

Yapılan analiz sonucunda çivitotu bitkisine uygulanan tuz konsantrasyonlarının incelenen tüm özellikler üzerine etkisi (yaprak kuru ağırlığı hariç) istatistiksel olarak önemli bulunmuştur (Çizelge 1). Tuz konsantrasyonu arttıkça kök yaş ağırlığ 1 azalmış $200 \mathrm{mM}$ 'lık tuz konsantrasyonunda en düşük seviyeye ulaşmıştır $(\mathrm{P}<0.05)$. Kök kuru ağırlığında $50 \mathrm{mM}$ konsantrasyondaki değer artışı ile bitki strese karşı tepki göstermiştir. Fakat daha sonra çevreye uyum sağlamıştır. Konsantrasyon arttıkça ağırlı değeri azalmış olsa da kontrol (0 mM), $100 \mathrm{mM}$ ve $200 \mathrm{mM}$ uygulamalar istatistiksel olarak aynı grupta yer almıştır $(\mathrm{P}<0.01)$ (Çizelge 1).

Kök oransal su içeriği bakımından en yüksek oran \% 81.77 ile kontrol grubu bitkilerinde, en düşük oran ise $\% 63.55$ ile $50 \mathrm{mM}$ konsantrasyona ait stres grubu bitkilerinde tespit edilmiştir $(\mathrm{P}<0.01)$. Tuz konsantrasyonu arttıkça yaprak yaş ağırlıklarında azalma meydana gelirken $(\mathrm{P}<0.05)$, yaprak kuru ağırlıkları arasındaki fark istatistiksel olarak önemsiz bulunmuştur $(\mathrm{P}>0.05)$. Yaprak oransal su içeriği değerleri 
kontrol grubuna göre düşük çıkmış, tuz derişimi arttıkça bir artış gözlenmiş olup uygulamalar arasında önemli bir fark oluşmuştur $(\mathrm{P}<0.01)$. I. tinctoria bitkisinin yapraklarından elde edilen en yüksek indigo miktarı kontrol grubu bitkilerinden elde edilmiş, stres grubu bitkilerinin indigo miktarları düşük bulunmuştur $(\mathrm{P}<0.01)$ (Çizelge 1). Plantago maritima ve Plantago media bitkileriyle yapılan bir çalışmada kök yaş ve kuru ağırlığı, gövde yaş ve kuru ağırlığının bitkiye uygulanan tuz konsantrasyonundaki artışa ve stres uygulama süresine bağl1 olarak azaldığ 1 tespit edilmiştir (Hediye 2009). Tagates erecta ve Petunia hybrida $40 \mathrm{mM}$, Gazania splendes $60 \mathrm{mM}$ tuza toleranslı bulunmuştur (Ayyıldız 2011). Geren ve ark. (2011), Lathyrus ochrus bitkisinde, artan tuz dozlarının kontrol uygulamasına göre incelenen özelliklerin tümünün olumsuz etkilendiğini belirtilmiştir.

\subsection{Kuraklık Stresi Uygulaması Sonuçları}

Kuraklık stresine maruz kalan çivitotu bitkilerinde, stresin incelenen tüm özellikler üzerine etkisi istatistiksel olarak önemli bulunmuştur (Çizelge 2). Stres uygulaması sonucunda kök yaş ağırlığ geçen gün sayısı arttıkça değerlerde düşüş gözlenmiştir. Stres gruplarında 3. ve 7 . günde kontrole göre düşüş olsa da, bitki kuraklığa toleranslı olmuş fakat 10 . gün susuzluktan etkilenmiş ve OSİ değerinde önemli bir düşüş meydana gelmiştir $(\mathrm{P}<0.01)$. Kuraklıkta geçen gün sayısı arttıkça stres grubundaki bitkilerin yaprak yaş ve kuru ağırlıkları da düşmüştür. $\mathrm{Bu}$ düşüş 10. günde en yüksek seviyeye ulaşmıştır. Kuraklık stresinin yapraktaki indigo üzerine etkisi incelendiğinde, stres uygulamalarında elde edilen indigonun kontrolden daha düşük olduğu görülmüş olup istatistiksel olarak da farklı gruplarda yer almışlardır $(\mathrm{P}<0.01)$ (Çizelge 2).

Mısır bitkisinde sulama suyu azaldıkça toprak üstü ve altı kuru madde veriminin azaldığ
2008). Pirinçle yapılan bir çalışmada, kuraklık stresinde bitki yaş ve kuru ağırlıklarının ciddi bir şekilde azaldığı tespit edilmiştir (Farooq ve ark. 2009). Sgherri ve ark. (2000), buğday bitkisinde toleranslı olan çeşidin hassas olanla karşılaştırıldığında, stres periyodu esnasında daha fazla OSİ'ye sahip olduğunu belirtmiştir. Bu çalışmada da bitkinin strese belli bir zamana kadar dayandığı fakat 10 . günde incelenen özelliklerde kontrole göre azalma meydana geldiği görülmüştür.

I. tinctoria'nın açık alanda, serada ve kontrollü ortamda yetiştirildiği bir çalışmada, açık alanda yetiştirilmiş bitkilerdeki indigo kazancının $400 \mathrm{mg} \mathrm{bitki}^{-1}$, serada $\left(150 \mathrm{mg} \mathrm{bitki}^{-1}\right)$ ve kontrollü ortamda (100 mg bitki $\left.{ }^{-1}\right)$ yetiştirilen bitkilerden daha fazla olduğu bildirilmiştir (Stoker ve ark. 1998). Campeol ve ark. (2006) I. tinctoria bitkisinin iyi sulanmış bitkilere göre su stresi koşullarında, hem yaprak ağırlığında hem de indigo veriminde düşüş meydana geldiğini bildirmişlerdir. Sales ve ark. (2006) Isatis bitkisindeki indigo değişimini iklimsel farklılıklarla açıklamışlardır. Daha kurak ve sıcak mevsimdeki indigo miktarındaki düşüşün, yüksek sıcaklığın bitki gelişimini sınırlandırmasından kaynaklandığını bildirmişlerdir. $\mathrm{Bu}$ çalışmada kuraklıkta kalma süresi arttıkça susuzluğa bağlı olarak indigo miktarında düşüş gözlenmiştir.

\subsection{Poliamin Uygulaması Sonuçları}

Poliamin uygulamasında en yüksek değerlerin elde edildiği putresinin tüm konsantrasyonları, kök yaş ağırlığını arttırmada en etkili poliamin olmuştur (Çizelge 3). Spermidin kontrole göre daha düşük, spermin ise kontrolle aynı grupta olduğundan bu iki poliaminin kök yaş ağırlığı üzerine bir etkisi olmamıştır $(\mathrm{P}<0.05)$. Kök kuru ağırlı̆̆ bakımından kontrol ile uygulamalar arasında önemli bir fark oluşmamıştır $(\mathrm{P}>0.05)$. Tüm poliamin uygulamaları OSİ üzerine olumlu katkı sağlamış, putresinin 2 $\mathrm{mM}$ (OSİ-\% 83.23) ve spermidinin $1 \mathrm{mM}$ (OSİ-\% 81.55) konsantrasyonları ise en etkili uygulamalar olmuştur $(\mathrm{P}<0.01)$.

Çizelge 1. Farklı tuz konsantrasyonlarının morfolojik özellikler ve indigo miktarı üzerine etkisi.

Table1. Effect of different salt concentrations on morphological properties and indigo amount.

\begin{tabular}{|c|c|c|c|c|c|}
\hline \multicolumn{2}{|c|}{ Tuz Konsantrasyonu (mM) } & 0 (Kontrol) & 50 & 100 & 200 \\
\hline \multirow{3}{*}{ 㐘 } & Yaş Ağırlığı (g)* & $2.02 \pm 0.34^{\mathrm{a}}$ & $1.63 \pm 0.17^{\mathrm{a}}$ & $1.19 \pm 0.28^{\mathrm{ab}}$ & $0.60 \pm 0.21^{b}$ \\
\hline & Kuru Ağırlığ $1(\mathrm{~g})^{* *}$ & $0.37 \pm 0.08^{b}$ & $0.70 \pm 0.01^{\mathrm{a}}$ & $0.32 \pm 0.08^{b}$ & $0.19 \pm 0.07^{b}$ \\
\hline & Oransal Su İçeriği $(\%)^{* *}$ & $81.77 \pm 2.33^{\mathrm{a}}$ & $63.55 \pm 2.17^{\mathrm{c}}$ & $72.85 \pm 0.26^{\mathrm{b}}$ & $67.94 \pm 1.66^{\mathrm{bc}}$ \\
\hline \multirow{4}{*}{ 苛 } & Yaş Ağırlı̆̆ ${ }_{1}(\mathrm{~g})^{*}$ & $3.92 \pm 0.49^{\mathrm{a}}$ & $2.61 \pm 0.30^{\mathrm{ab}}$ & $1.69 \pm 0.43^{b}$ & $1.72 \pm 0.48^{b}$ \\
\hline & Kuru Ağırlı̆̆ı (g) & $0.75 \pm 0.10$ & $0.72 \pm 0.16$ & $0.47 \pm 0.11$ & $0.41 \pm 0.08$ \\
\hline & Oransal Su İçeriği (\%)** & $80.76 \pm 1.26^{\mathrm{a}}$ & $68.49 \pm 0.49^{c}$ & $71.58 \pm 0.82^{\mathrm{bc}}$ & $74.73 \pm 2.52^{b}$ \\
\hline & İndigo $\left(\mathrm{mg} \mathrm{g}^{-1}\right)^{* *}$ & $0.68 \pm 0.07^{\mathrm{a}}$ & $0.42 \pm 0.04^{\mathrm{b}}$ & $0.48 \pm 0.06^{\mathrm{ab}}$ & $0.46 \pm 0.05^{b}$ \\
\hline
\end{tabular}

Çizelge 2. Kuraklık stresinin morfolojik özellikler ve indigo miktarı üzerine etkisi.

Table 2. Effect of drought stress on morphological properties and indigo amount.

\begin{tabular}{|c|c|c|c|c|c|}
\hline \multicolumn{2}{|c|}{ Kuraklığa Bırakılan Gün Sayısı } & Uygulama & 3. gün & 7. gün & 10. gün \\
\hline \multirow{6}{*}{ 商 } & \multirow{2}{*}{ Yaş Ağırlığ $(\mathrm{g})^{* *}$} & Kontrol & $4.33 \pm 0.93^{\mathrm{a}}$ & $3.45 \pm 0.80^{\mathrm{ab}}$ & $1.63 \pm 0.30^{\mathrm{bc}}$ \\
\hline & & Stres & $2.98 \pm 0.12^{\mathrm{ab}}$ & $2.74 \pm 0.53^{\mathrm{ab}}$ & $0.84 \pm 0.09^{\mathrm{c}}$ \\
\hline & \multirow{2}{*}{ Kuru Ağırlığı (g)* } & Kontrol & $0.58 \pm 0.12^{\mathrm{a}}$ & $0.50 \pm 0.15^{\mathrm{a}}$ & $0.19 \pm 0.05^{b}$ \\
\hline & & Stres & $0.58 \pm 0.01^{\mathrm{a}}$ & $0.56 \pm 0.12^{\mathrm{a}}$ & $0.27 \pm 0.03^{\mathrm{ab}}$ \\
\hline & \multirow{2}{*}{ Oransal Su İçeriği (\%)** } & Kontrol & $86.61 \pm 0.87^{\mathrm{ab}}$ & $85.80 \pm 0.86^{\mathrm{b}}$ & $88.77 \pm 0.76^{\mathrm{a}}$ \\
\hline & & Stres & $80.49 \pm 0.41^{\mathrm{c}}$ & $79.34 \pm 1.71^{\mathrm{c}}$ & $67.35 \pm 0.52^{d}$ \\
\hline \multirow{8}{*}{ 㫕 } & \multirow{2}{*}{ Yaş Ağırlığı $(g)^{* *}$} & Kontrol & $23.32 \pm 3.96^{\mathrm{a}}$ & $18.23 \pm 4.78^{\mathrm{ab}}$ & $14.42 \pm 2.18^{\mathrm{ab}}$ \\
\hline & & Stres & $12.38 \pm 2.12^{b}$ & $9.06 \pm 1.53^{\mathrm{bc}}$ & $2.22 \pm 0.85^{\mathrm{c}}$ \\
\hline & \multirow{2}{*}{ Kuru Ağırlığı (g)* } & Kontrol & $2.56 \pm 0.45^{\mathrm{a}}$ & $1.94 \pm 0.43^{\mathrm{ab}}$ & $1.76 \pm 0.35^{\mathrm{abc}}$ \\
\hline & & Stres & $1.53 \pm 0.25^{\mathrm{abc}}$ & $1.30 \pm 0.19^{\mathrm{bc}}$ & $0.70 \pm 0.24^{\mathrm{c}}$ \\
\hline & \multirow{2}{*}{ Oransal Su İçeriği $(\%)^{* *}$} & Kontrol & $88.97 \pm 0.56^{\mathrm{a}}$ & $89.14 \pm 0.43^{\mathrm{a}}$ & $88.02 \pm 1.00^{\mathrm{a}}$ \\
\hline & & Stres & $87.57 \pm 0.22^{\mathrm{a}}$ & $85.49 \pm 0.55^{\mathrm{a}}$ & $67.26 \pm 2.68^{b}$ \\
\hline & \multirow{2}{*}{ İndigo $\left(\mathrm{mg} \mathrm{g}^{-1}\right)^{* *}$} & Kontrol & $2.10 \pm 0.23^{\mathrm{a}}$ & $1.52 \pm 0.11^{\mathrm{bc}}$ & $1.30 \pm 0.12^{\mathrm{c}}$ \\
\hline & & Stres & $1.96 \pm 0.30^{\mathrm{ab}}$ & $0.78 \pm 0.16^{\mathrm{d}}$ & $0.35 \pm 0.10^{d}$ \\
\hline
\end{tabular}


Yaprak yaş ağırlığı bakımından, putresinin tüm ve spermidinin 1 mM'lı konsantrasyonları kontrole ve diğer poliamin uygulamalarına göre daha yüksek çıkarken, yaprak kuru ağırlığ 1 arasındaki farklar istatistiki olarak önemsiz bulunmuştur $(\mathrm{P}>0.05)$. Tüm poliamin uygulamalarının bitkinin yaprak oransal su içeriğini arttırdığı gözlenmiştir $(\mathrm{P}<0.01)$. İndigo verimi bakımından en yüksek değerler spermin ve putresin uygulamalarından elde edilmiş olup, spermidin hormonunun etkili olmadığı görülmektedir $(\mathrm{P}<0.01)$ (Çizelge 3). Gerek fide ağırlığının gerekse indigo miktarının artışı noktasında putresinin olumlu bir etkisinin olduğu gayet açıktır. $\mathrm{Bu}$ da poliamin uygulamalarının indigo miktarını artırmada önemli bir rol oynadığını gösterir. Fide ağırlığının artışı, birim alandan elde edilen yaprak veriminin ve indigo da yapraklardan elde edildiğinden dolayı, buna paralel olarak indigo veriminin artışıyla ilişkilidir.

Ocimum basilicum spermin, spermidin ve putresin uygulamalarının düşük konsantrasyonunda daha verimli sonuç elde edildiği bildirilmiştir (Karaman ve ark. 2008).

\subsection{Poliamin+Tuz Stresi Uygulaması Sonuçları}

Tuz stresi altındaki I. tinctoria bitkisinin kök yaş ve kuru ağırlıkları üzerine poliamin uygulamalarının etkisi önemli bulunmazken $(\mathrm{P}>0.05)$, OSİ değerlerini arttırdığı görülmüştür $(\mathrm{P}<0.01)$ (Çizelge 4). Yaprak yaş ağırlığında putresinin tüm uygulamaları ile spermidinin 0.1 ve1 mM'lık konsantrasyonları kontrol gruplarına göre yüksek çıkmıştır $(\mathrm{P}<0.05)$, ancak poliaminlerin yaprak kuru ağırlığı üzerine etkisi önemsiz bulunmuştur $(\mathrm{P}>0.05)$. Tüm poliamin uygulamalarının yaprak oransal su içeriği üzerine etkisi olumlu olmuş $(\mathrm{P}<0.05)$, poliamin uygulamaları bitkinin tuza toleransını arttırmıștır. Poliamin+tuz stresi uygulamalarında indigo miktarını en çok artıran putresin iken en az etkili olan spermidin olmuştur. Spermin konsantrasyonu arttıkça indigo miktarında da artış olmuştur ( $\mathrm{P}<0.01)$ (Çizelge 4).
Chamomilla recutita ve Origanum majorana yapraklarına spreyleme ile uygulanan $0.1 \mathrm{mM}$ konsantrasyonda putresin, spermidin ve sperminin tuzluluğun etkilerini dengelediği bildirilmiştir (Ali ve ark. 2007). Tuzun, Helianthus annuus L. var. santafe tohumlarının çimlenmesini engellediğini ya da geciktirdiğini fakat putresin+tuz uygulamalarında putresinin tuz stresine toleransı arttırarak çimlenme ve büyüme parametreleri üzerinde olumlu etkileri olduğu görülmüştür (Bozcuk ve Tekin 1996). Aynı bitki üzerinde yapılan çalışmada $0.1 \mathrm{mM}$ sperminin $200 \mathrm{mM}$ tuz uygulamasının olumsuz etkilerini ortadan kaldırdığ bildirilmiştir (Mutlu ve Bozcuk 2000). Ayrıca H. annuus L. var. santafe'nin yaprak alanı üzerine tuzun negatif etkisini putresinin engellediği bildirilmiştir (Mutlu ve Bozcuk 2013). Bu çalışmada elde edilen sonuçlar da putresinin tuz stresine karşı koymada etkili olduğunu göstermektedir.

\subsection{Poliamin+Kuraklık Stresi Uygulamaları Sonuçları}

Poliamin+kuraklık stresi uygulamalarının $I$. tinctoria bitkilerinde kök kuru ve yaş ağırlığı üzerine etkileri istatistiksel olarak önemsiz bulunurken $(\mathrm{P}>0.05)$, tüm poliamin uygulamalarına ait kök oransal su içeriği değerleri kontrol gruplarından önemlilik arzedecek şekilde yüksek çıkmıştır $(\mathrm{P}<0.01)$ (Çizelge 5). Poliamin+kuraklık uygulamasında yaprak yaş ağırlı̆̆ı değerlerini, poliamin uygulamalarının kontrole nazaran arttırdığı, sperminin ise daha etkili olduğu görülmüştür $(\mathrm{P}<0.05)$. Yaprak kuru ağırlığında tüm poliamin konsantrasyonları kontrol grubundan yüksek çıkmış olsa da, değerler arasındaki farklılık istatistiki olarak önemsiz bulunmuştur $(\mathrm{P}>0.05)$. Yaprak oransal su içeriği verileri kontrol grubu değerlerinden yüksek bulunmuştur $(\mathrm{P}<0.01)$. Kuraklık stresine karşı indigo miktarının artırılmasında en etkili poliamin spermin olurken, spermidin ve putresin de kontrole göre daha iyi sonuçlar vermiştir. En etkili konsantrasyon spermin ve spermidinde $1 \mathrm{mM}$, putresinde $0.1 \mathrm{mM}$ 'lık uygulama olmuştur $(\mathrm{P}<0.01)$ (Çizelge 5).

Çizelge 3. Eksojen poliaminlerin morfolojik özellikler ve indigo miktarı üzerine etkisi.

Table 3. Effect of exogenous polyamines on morphological properties and indigo amount.

\begin{tabular}{|c|c|c|c|c|c|c|}
\hline \multirow{11}{*}{ 落 } & Poliamin & Konsantrasyon & Yaş Ağırlık* & Kuru Ağırlık & Oransal Su İçeriği** & İndigo $\left(\mathrm{mg} \mathrm{g}^{-1}\right)^{* * *}$ \\
\hline & & $0.1 \mathrm{mM}$ & $0.35 \pm 0.02^{\mathrm{ab}}$ & $0.10 \pm 0.01$ & $73.71 \pm 0.01^{\mathrm{c}}$ & - \\
\hline & Spermin & $1 \mathrm{mM}$ & $0.33 \pm 0.08^{\mathrm{ab}}$ & $0.08 \pm 0.01$ & $76.67 \pm 0.41^{\mathrm{bc}}$ & - \\
\hline & & $2 \mathrm{mM}$ & $0.37 \pm 0.03^{\mathrm{ab}}$ & $0.10 \pm 0.01$ & $73.73 \pm 0.84^{\mathrm{c}}$ & - \\
\hline & & $0.1 \mathrm{mM}$ & $0.26 \pm 0.07^{\mathrm{b}}$ & $0.06 \pm 0.01$ & $75.91 \pm 1.66^{\mathrm{bc}}$ & - \\
\hline & Spermidin & $1 \mathrm{mM}$ & $0.45 \pm 0.10^{a b}$ & $0.08 \pm 0.02$ & $81.55 \pm 0.01^{\mathrm{a}}$ & - \\
\hline & & $2 \mathrm{mM}$ & $0.27 \pm 0.01^{\mathrm{b}}$ & $0.06 \pm 0.01$ & $78.26 \pm 0.94^{b}$ & - \\
\hline & & $0.1 \mathrm{mM}$ & $0.56 \pm 0.06^{\mathrm{a}}$ & $0.13 \pm 0.01$ & $75.27 \pm 1.23^{\mathrm{bc}}$ & - \\
\hline & Putresin & $1 \mathrm{mM}$ & $0.56 \pm 0.09^{\mathrm{a}}$ & $0.12 \pm 0.01$ & $77.91 \pm 0.51^{\mathrm{b}}$ & - \\
\hline & & $2 \mathrm{mM}$ & $0.68 \pm 0.34^{\mathrm{a}}$ & $0.07 \pm 0.01$ & $83.23 \pm 0.82^{\mathrm{a}}$ & - \\
\hline & Kontrol & $0 \mathrm{mM}$ & $0.32 \pm 0.04^{\mathrm{ab}}$ & $0.09 \pm 0.01$ & $70.58 \pm 0.95^{\mathrm{d}}$ & - \\
\hline \multirow{10}{*}{ 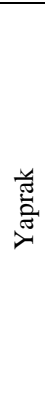 } & & $0.1 \mathrm{mM}$ & $2.79 \pm 0.04^{\mathrm{ab}}$ & $0.34 \pm 0.01$ & $87.82 \pm 0.04^{b c}$ & $0.63 \pm 0.07^{\mathrm{ab}}$ \\
\hline & Spermin & $1 \mathrm{mM}$ & $3.17 \pm 0.32$ ab & $0.30 \pm 0.04$ & $90.39 \pm 0.35^{\mathrm{ab}}$ & $0.80 \pm 0.08^{\mathrm{a}}$ \\
\hline & & $2 \mathrm{mM}$ & $2.78 \pm 0.28 \mathrm{ab}$ & $0.34 \pm 0.02$ & $87.82 \pm 0.67^{\mathrm{bc}}$ & $0.59 \pm 0.12^{a b}$ \\
\hline & & $0.1 \mathrm{mM}$ & $2.08 \pm 0.58^{a b}$ & $0.21 \pm 0.05$ & $89.86 \pm 0.27^{\mathrm{ab}}$ & $0.31 \pm 0.04^{\mathrm{c}}$ \\
\hline & Spermidin & $1 \mathrm{mM}$ & $4.56 \pm 1.27^{\mathrm{a}}$ & $0.37 \pm 0.11$ & $92.05 \pm 0.31^{\mathrm{a}}$ & $0.41 \pm 0.05^{\mathrm{bc}}$ \\
\hline & & $2 \mathrm{mM}$ & $1.60 \pm 0.00^{\mathrm{b}}$ & $0.18 \pm 0.00$ & $88.87 \pm 0.04^{\mathrm{bc}}$ & $0.39 \pm 0.04^{\mathrm{bc}}$ \\
\hline & & $0.1 \mathrm{mM}$ & $4.21 \pm 0.61^{\mathrm{a}}$ & $0.51 \pm 0.07$ & $88.03 \pm 0.12^{\mathrm{bc}}$ & $0.58 \pm 0.13^{\mathrm{ab}}$ \\
\hline & Putresin & $1 \mathrm{mM}$ & $3.84 \pm 0.03^{\mathrm{a}}$ & $0.46 \pm 0.01$ & $88.15 \pm 0.29^{c}$ & $0.60 \pm 0.10^{\mathrm{b}}$ \\
\hline & & $2 \mathrm{mM}$ & $3.62 \pm 0.78^{a b}$ & $0.27 \pm 0.13$ & $93.05 \pm 2.90^{\mathrm{a}}$ & $0.59 \pm 0.08^{a b}$ \\
\hline & Kontrol & $0 \mathrm{mM}$ & $2.09 \pm 0.31^{\mathrm{ab}}$ & $0.41 \pm 0.05$ & $79.83 \pm 0.61^{\mathrm{d}}$ & $0.30 \pm 0.03^{\mathrm{c}}$ \\
\hline
\end{tabular}


Çizelge 4. Poliamin+tuz stresi uygulamasının morfolojik özellikler ve indigo miktarı üzerine etkisi.

Table 4. Effect of polyamine+salt stress application on morphological properties and indigo amount.

\begin{tabular}{|c|c|c|c|c|c|c|}
\hline \multirow{12}{*}{ 荇 } & Poliamin & Konsantrasyon & Yaş Ağırlık & Kuru Ağırlık & Oransal Su İçeriği*** & İndigo $\left(\mathrm{mg} \mathrm{g}^{-1}\right)^{* *}$ \\
\hline & \multirow{3}{*}{ Spermin } & $0.1 \mathrm{mM}$ & $0.10 \pm 0.02$ & $0.02 \pm 0.01$ & $75.91 \pm 1.02^{\mathrm{ab}}$ & - \\
\hline & & $1 \mathrm{mM}$ & $0.14 \pm 0.04$ & $0.04 \pm 0.01$ & $66.45 \pm 2.19^{\mathrm{cd}}$ & - \\
\hline & & $2 \mathrm{mM}$ & $0.18 \pm 0.12$ & $0.05 \pm 0.04$ & $71.80 \pm 1.39^{a b c}$ & - \\
\hline & \multirow{3}{*}{ Spermidin } & $0.1 \mathrm{mM}$ & $0.22 \pm 0.07$ & $0.07 \pm 0.02$ & $69.10 \pm 1.50^{\mathrm{abc}}$ & - \\
\hline & & $1 \mathrm{mM}$ & $0.19 \pm 0.06$ & $0.06 \pm 0.02$ & $71.42 \pm 1.44^{\mathrm{abc}}$ & - \\
\hline & & $2 \mathrm{mM}$ & $0.09 \pm 0.02$ & $0.02 \pm 0.01$ & $76.31 \pm 1.00^{\mathrm{a}}$ & - \\
\hline & \multirow{3}{*}{ Putresin } & $0.1 \mathrm{mM}$ & $0.27 \pm 0.14$ & $0.08 \pm 0.04$ & $72.66 \pm 1.92^{a b c}$ & - \\
\hline & & $1 \mathrm{mM}$ & $0.12 \pm 0.03$ & $0.03 \pm 0.01$ & $74.49 \pm 2.71^{\mathrm{ab}}$ & - \\
\hline & & $2 \mathrm{mM}$ & $0.15 \pm 0.07$ & $0.05 \pm 0.03$ & $68.89 \pm 2.82^{\mathrm{bc}}$ & - \\
\hline & Kontrol 1 & $0 \mathrm{mM}$ & $0.22 \pm 0.08$ & $0.08 \pm 0.03$ & $65.71 \pm 0.72^{\mathrm{cd}}$ & - \\
\hline & Kontrol 2 & $0 \mathrm{mM}$ & $0.10 \pm 0.01$ & $0.04 \pm 0.00$ & $60.43 \pm 4.43^{\mathrm{d}}$ & - \\
\hline \multirow{11}{*}{ 范 } & \multirow{3}{*}{ Spermin } & $0.1 \mathrm{mM}$ & $0.81 \pm 0.16^{b c}$ & $0.10 \pm 0.03$ & $88.00 \pm 1.33^{a}$ & $4.18 \pm 0.08^{\mathrm{cd}}$ \\
\hline & & $1 \mathrm{mM}$ & $0.71 \pm 0.20^{c}$ & $0.11 \pm 0.02$ & $86.69 \pm 0.23^{a b}$ & $4.46 \pm 0.07^{b c}$ \\
\hline & & $2 \mathrm{mM}$ & $0.80 \pm 0.10^{\mathrm{bc}}$ & $0.13 \pm 0.02$ & $84.04 \pm 0.27^{\text {ab }}$ & $4.68 \pm 0.18^{a b}$ \\
\hline & \multirow{3}{*}{ Spermidin } & $0.1 \mathrm{mM}$ & $1.90 \pm 0.44^{\mathrm{a}}$ & $0.27 \pm 0.08$ & $86.08 \pm 0.97^{a}$ & $3.07 \pm 0.22^{\mathrm{e}}$ \\
\hline & & $1 \mathrm{mM}$ & $1.50 \pm 0.20^{\mathrm{abc}}$ & $0.22 \pm 0.03$ & $85.26 \pm 0.83^{a b}$ & $3.13 \pm 0.12^{\mathrm{e}}$ \\
\hline & & $2 \mathrm{mM}$ & $0.78 \pm 0.09^{\mathrm{bc}}$ & $0.12 \pm 0.01$ & $84.89 \pm 0.56^{\mathrm{ab}}$ & $3.20 \pm 0.21^{\mathrm{e}}$ \\
\hline & \multirow{3}{*}{ Putresin } & $0.1 \mathrm{mM}$ & $1.84 \pm 0.53^{a b}$ & $0.27 \pm 0.08$ & $85.34 \pm 0.33^{a b}$ & $5.03 \pm 0.18^{a}$ \\
\hline & & $1 \mathrm{mM}$ & $1.53 \pm 0.38^{a b c}$ & $0.23 \pm 0.07$ & $84.48 \pm 1.07^{\mathrm{ab}}$ & $4.82 \pm 0.16^{\mathrm{ab}}$ \\
\hline & & $2 \mathrm{mM}$ & $1.49 \pm 0.57^{\mathrm{abc}}$ & $0.24 \pm 0.10$ & $84.08 \pm 1.82^{a b}$ & $4.94 \pm 0.11^{\mathrm{ab}}$ \\
\hline & Kontrol 1 & $0 \mathrm{mM}$ & $1.20 \pm 0.10^{\mathrm{abc}}$ & $0.22 \pm 0.01$ & $81.18 \pm 0.59^{\mathrm{bc}}$ & $3.91 \pm 0.17^{\mathrm{d}}$ \\
\hline & Kontrol 2 & $0 \mathrm{mM}$ & $0.91 \pm 0.10^{\mathrm{abc}}$ & $0.21 \pm 0.06$ & $77.86 \pm 3.77^{c}$ & $2.45 \pm 0.12^{\mathrm{f}}$ \\
\hline
\end{tabular}

Kontrol 1: Poliamin uygulanmadan saf su ile sulanmış bitkiler.

Kontrol 2: Poliamin uygulanmadan $200 \mathrm{mM}$ tuzlu su ile sulanmış bitkiler.

*: $\mathrm{P}<0.05 ;$ **: $\mathrm{P}<0.01$

Çizelge 5. Poliamin+kuraklık stresi uygulamasının morfolojik özellikler ve indigo miktarı üzerine etkisi.

Table 5. Effect of application of polyamine+drought stress on morphological properties and indigo amount.

\begin{tabular}{|c|c|c|c|c|c|c|}
\hline \multirow{11}{*}{$\begin{array}{l}y \\
\vdots 0 \\
10\end{array}$} & Poliamin & Konsantrasyon & Yaș Ağırlık * & Kuru Ağırlık & Oransal Su İçeriği*, ** & İndigo $\left(\mathrm{mg} \mathrm{g}^{-1}\right)^{* *}$ \\
\hline & \multirow{3}{*}{ Spermin } & $0.1 \mathrm{mM}$ & $0.22 \pm 0.14$ & $0.06 \pm 0.04$ & $74.72 \pm 3.33^{\mathrm{a}}$ & - \\
\hline & & $1 \mathrm{mM}$ & $0.19 \pm 0.16$ & $0.05 \pm 0.05$ & $73.25 \pm 2.22^{\mathrm{ab}}$ & - \\
\hline & & $2 \mathrm{mM}$ & $0.22 \pm 0.05$ & $0.07 \pm 0.02$ & $69.35 \pm 2.19^{\mathrm{bc}}$ & - \\
\hline & \multirow{3}{*}{ Spermidin } & $0.1 \mathrm{mM}$ & $0.23 \pm 0.03$ & $0.07 \pm 0.01$ & $69.66 \pm 0.54 \mathrm{abc}$ & - \\
\hline & & $1 \mathrm{mM}$ & $0.11 \pm 0.01$ & $0.03 \pm 0.00$ & $73.54 \pm 0.38^{a b}$ & - \\
\hline & & $2 \mathrm{mM}$ & $0.19 \pm 0.14$ & $0.06 \pm 0.05$ & $69.07 \pm 1.90^{\mathrm{bc}}$ & - \\
\hline & \multirow{3}{*}{ Putresin } & $0.1 \mathrm{mM}$ & $0.16 \pm 0.02$ & $0.04 \pm 0.01$ & $72.84 \pm 0.55^{b}$ & - \\
\hline & & $1 \mathrm{mM}$ & $0.14 \pm 0.04$ & $0.04 \pm 0.01$ & $74.03 \pm 1.09^{a b}$ & - \\
\hline & & $2 \mathrm{mM}$ & $0.19 \pm 0.02$ & $0.05 \pm 0.01$ & $74.76 \pm 0.64^{\mathrm{a}}$ & - \\
\hline & Kontrol & $0 \mathrm{mM}$ & $0.08 \pm 0.01$ & $0.02 \pm 0.00$ & $65.59 \pm 0.86^{\mathrm{d}}$ & - \\
\hline \multirow{10}{*}{ 慶 } & \multirow{3}{*}{ Spermin } & $0.1 \mathrm{mM}$ & $2.86 \pm 1.06^{\mathrm{a}}$ & $0.36 \pm 0.18$ & $87.94 \pm 1.70^{\mathrm{ab}}$ & $4.18 \pm 0.18^{b}$ \\
\hline & & $1 \mathrm{mM}$ & $1.48 \pm 0.50^{\mathrm{ab}}$ & $0.20 \pm 0.10$ & $87.23 \pm 2.51^{\mathrm{ab}}$ & $4.84 \pm 0.13^{\mathrm{a}}$ \\
\hline & & $2 \mathrm{mM}$ & $2.58 \pm 0.18^{\mathrm{a}}$ & $0.39 \pm 0.05$ & $85.90 \pm 1.15^{b}$ & $4.70 \pm 0.15^{\mathrm{a}}$ \\
\hline & \multirow{3}{*}{ Spermidin } & $0.1 \mathrm{mM}$ & $2.69 \pm 0.41^{\mathrm{a}}$ & $0.30 \pm 0.04$ & $88.91 \pm 0.27^{\mathrm{ab}}$ & $4.09 \pm 0.16^{b}$ \\
\hline & & $1 \mathrm{mM}$ & $1.71 \pm 0.28^{\mathrm{ab}}$ & $0.18 \pm 0.03$ & $89.36 \pm 0.10^{a}$ & $4.87 \pm 0.17^{\mathrm{a}}$ \\
\hline & & $2 \mathrm{mM}$ & $1.44 \pm 0.56^{\mathrm{ab}}$ & $0.19 \pm 0.10$ & $87.67 \pm 2.21^{\mathrm{ab}}$ & $4.41 \pm 0.23^{a b}$ \\
\hline & \multirow{3}{*}{ Putresin } & $0.1 \mathrm{mM}$ & $1.67 \pm 0.12^{\mathrm{ab}}$ & $0.20 \pm 0.02$ & $88.06 \pm 0.42^{a b}$ & $4.71 \pm 0.21^{\mathrm{a}}$ \\
\hline & & $1 \mathrm{mM}$ & $1.80 \pm 0.65^{\mathrm{ab}}$ & $0.22 \pm 0.07$ & $87.69 \pm 0.48^{a b}$ & $4.46 \pm 0.12^{a b}$ \\
\hline & & $2 \mathrm{mM}$ & $1.97 \pm 0.21^{\mathrm{ab}}$ & $0.22 \pm 0.01$ & $88.59 \pm 0.41^{\mathrm{ab}}$ & $4.02 \pm 0.16^{\mathrm{b}}$ \\
\hline & Kontrol & $0 \mathrm{mM}$ & $0.92 \pm 0.23^{b}$ & $0.16 \pm 0.04$ & $82.14 \pm 0.92^{\mathrm{c}}$ & $3.54 \pm 0.10^{c}$ \\
\hline
\end{tabular}

Buğday bitkilerinin poliamin+yüksek sıcaklık stresine maruz bırakıldığı bir çalışmada kontrol grubundaki (poliamin uygulanmamış) bitkilerin gövde yaş ve kuru ağırlıklarında azalma meydana gelirken, putresin uygulanan bitkilerde gövde yaş ve kuru ağırlıkları ile oransal su içeriklerinin önemli derecede arttığı bulunmuştur (Hassanein ve ark. 2013). Pirinç bitkisine yapılan kuraklık+poliamin uygulaması sonucunda gövde yaş ağırlığı, oransal su içeriği verilerinde en yüksek değer 
spermin hormonundan elde edilmiştir (Farooq ve ark. 2009). Bu çalışmada da poliamin+kuraklık stresi safhasında kök oransal su içeriği, gövde yaş ve kuru ağırlığı, indigo değerleri için en etkili sonuçlar spermin hormonundan elde edilmiştir.

\section{Sonuc}

Çevresel stres koşullarının ve poliaminlerin bitkilerin sekonder madde içeriğine etkilerinin olduğu bilinmektedir. Giderek kuraklaşan dünyamızda toprağın tuzluluk durumunun artması ve su stresinin olması, karşılaşılması en muhtemel çevresel stres faktörlerindendir. Mavi boya kaynağ I. tinctoria ile ilgili bu konuda neredeyse hiç çalışma yoktur. Bu çalışma çivitotunun kuraklığa ve tuzluluğa tolerans derecesi ve adaptasyon kabiliyetinin araştırıldığı ilk çalışmadır. $\mathrm{Bu}$ çalışmada $I$. tinctoria bitkisinin yapraklarındaki indigonun çevresel şartlardan ne düzeyde etkilendiği araştırılmış ve indigonun miktarını arttırmaya yönelik çalışmalar yapılmıştır. Çivitotu bitkisi, tuz stresi uygulamasında, artan tuz dozlarından kontrole göre olumsuz etkilense de, bitki genelde tuzu tolere edebilmiş fakat $200 \mathrm{mM}$ konsantrasyonda bitkinin negatif olarak etkilendiği ve ağırlık kaybı yaşadığı görülmüştür. Kuraklık stresi uygulamalarında strese bırakılan gün sayıs1 arttıkça indigo değeri ve diğer verilerde azalma olmuşsa da 10. güne kadar bitki stresle savaşmıştır. Poliamin uygulamasında gerek fide ağırlığının gerekse indigo miktarının verim artışında putresinin olumlu bir etkisinin olduğu görülmüştür. Poliamin+tuz stresi uygulamalarında indigo miktarını en çok artıran ve etkili olan poliamin spermin ve putresin olmuştur. Kuraklık stresine karşı indigo miktarının artırılmasında en etkili poliamin spermin olurken, spermidin ve putresin de kontrole göre daha iyi sonuçlar vermiştir. $\mathrm{Bu}$ da poliamin uygulamalarının indigo miktarını artırmada önemli bir rol oynadığını göstermektedir. Sentetik indigoyla yarışabilmesi için, I. tinctoria bitkisinin indigo verimini ve kalitesini arttırmak çok önemlidir. Artan çevre kirliliği ve buna paralel olarak gelişen çevre duyarlılığı doğal materyalleri ön plana çıkarmakta ve doğal olanın sentetikle yarışabilmesi adına bu tarz çalışmaların önemi daha da artmaktadır.

\section{Teșekkür}

Yazarlar çalışmaya maddi destek sağlayan KSÜ Bilimsel Araştırma Projeleri Koordinasyon Birimi'ne teşekkür eder (Proje No: 2014/2-2YLS).

\section{Kaynaklar}

Aksoy E (2008) Effect of Drought and Salt Stresses on The Gene Expression Levels of Antioxidant Enzymes in Lentil (Lens culinaris M.) Seedlings. Yüksek Lisans Tezi, Orta Doğu Teknik Üniversitesi Fen Bilimleri Enstitüsü, Ankara.

Ali RM, Abbas HM, Kamal RK (2007) The Effects of Treatment with Polyamines on Dry Matter, Oil and Flavonoid Contents in Salinity Stressed Chamomile and Sweet Marjoram. Plant Soil Environment 53(12): 529-543.

Ayyıldız L (2011) Mevsimlik Çiçeklerde Tuzun Bitki Gelişimi Üzerine Etkisinin Belirlenmesi. Yüksek Lisans Tezi, Yüzüncü Yıl Üniversitesi Fen Bilimleri Enstitüsü, Van.

Battal P, Erman M, Çelik İ, Berber İ, Türker M, Erez ME, Oğuz F (2007) Kuraklık Stresi Altında Yetiştirilen Bazı Mercimek (Lens culinaris Medik.) Çeşitlerinde Moleküler ve Fizyolojik Değişikliklerin Araştırılması. Proje No: TBAG- 2294 (103T070).

Bek Y, Efe E (1995) Araştırma Metotları. Çukurova Üniversitesi, Ziraat Fakültesi Ders Kitabı, Yayın No: 71, Adana.
Binici AS (2005) Tuzlu Koşullarda Yetișen Buğday Bitkisinin Fizyolojik ve Bazı Besin Elementlerinin Alımı Üzerine Gibberellik ve Absisik Asitlerin Etkileri. Yüksek Lisans Tezi, Harran Üniversitesi Fen Bilimleri Enstitüsü, Şanlıurfa.

Bozcuk S, Tekin F (1996) Helianthus annuиs L. Tohumlarının Çimlenmesi ve Fide Gelişimi Üzerine Tuz ve Ekzojen Poliaminlerin Etkisi, Ankara. Proje No: TBAG-1265.

Campeol E, Angelini LG, Tozzi S, Bertolacci M (2006) Seasonal variation of indigo precursors in Isatis tinctoria L. and Polygonum tinctorium Ait. as affected by water deficit. Environmental and Experimental Botany 58: 223-233.

Comlekcioglu N, Efe L, Karaman S (2015) Extraction of Indigo from Some Isatis species and Dyeing Standardization Using Lowtechnology Methods. Brazilian Archives of Biology and Technology 58(1): 96-102.

Farooq M, Wahid A, Lee D (2009) Exogenously applied polyamines increase drought tolerance of rice by improving leaf water status, photosynthesis and membrane properties. Acta Physiologiae Plantarum 31: 937-945.

Geren H, Okkaoğlu H, Avcıoğlu R (2011) Mikorizanın Farklı Tuz (NaCl) Konsantrasyonlarında Kıbrıs Mürdümüğü (Lathyrus ochrus)'nün Verim ve Bazı Fizyolojik Özellikleri Üzerine Etkisi. Ege Üniversitesi Ziraat Fakültesi Dergisi 48(1): 31-37.

Gilbert KG, Maule HG, Rudolph B, Lewis M, Vandenburg H, Sales E, Cooke DT (2004) Quantitative analysis of indigo and indigo precursors in leaves of Isatis spp. and Polygonum tinctorium. Biotechnology progress 20(4): 1289-1292.

Gönüz A, Aksoy A, Karabacak E (2006) Çanakkale ve Çevresinde Doğal Yayılış Gösteren Bazı Potansiyel Boya Bitkileri. Anadolu Ege Tarımsal Araştırma Enstitüsü Dergisi 16(1): 54-71.

Güneș M, Aktaş M (2008) Su Stresinde Yetiștirilen Genç Mısır Bitkisinde Potasyum Uygulamasının Gelişme ve Verim Üzerine Etkisi. Harran Üniversitesi Ziraat Fakültesi Dergisi 12(2): 33-36.

Hassanein RA, El-Khawas SA, Ibrahim SK, El-Bassiouny HM, Mostafa HA, Abd El-Monem AA (2013) Improving the thermo tolerance of wheat plant by foliar application of arginine or putrescine. International Journal of Molecular Sciences 45(1): 111-118.

Hediye ASE (2009) Tuz Stresinin Farklı Tuz Toleransına Sahip İki Plantago Türünün Fizyolojik ve Biyokimyasal Özellikleri Üzerine Etkilerinin Araştırılması. Doktora Tezi, Ege Üniversitesi Fen Bilimleri Enstitüsü, İzmir.

Kaya MD, Okçu G, Atak M, Çıkılı Y, Kolsarıı Ö (2006) Seed treatments to overcome salt and drought stress during germination in sunflower (Helianthus annuиs L.). European Journal of Agronomy 24(4): 291-295.

Khajeh-Hosseini M, Powell AA, Bingham IJ (2003) The interaction between salinity stress and seed vigour during germination of soybean seeds. Seed Science and Technology 31: 715-725.

Karaman S, Kirecci OA, Ilcim A (2008) Influence of polyamines (spermine, spermidine and putrescine) on the essential oil composition of basil (Ocimum basilicum L.) Journal of Essential Oil Research 20(4): 288-292.

Korkmaz A (2008) Biberde Çimlenme ve Fide Gelişimi Sırasında Üşüme Stresine Karşı Toleransın 5-Aminolevulinik Asit (ALA) Uygulamaları İle Arttrrılması, Tübitak Proje No: 107 O 611.

Kreczmer B, Filek M, Otto I, Chwistek-Rog L, Biesaga-Koscielniak JB (2013) Arguments in Favour of the Involment of Polyamines in Flowering Induction of Winter Rape (Brassica napus L. var. oleifera) During Vernazilation and Grafting. Acta Scientiarum Polonorum Agricultura 12(4): 73-83.

Mutlu F, Bozcuk S (2000) Tuzlu Koşullarda Ayçiçeği Tohumlarının Çimlenmesi ve Erken Büyüme Üzerine Dışsal Sperminin Etkileri. Turkish Journal of Biology 24: 635-643. 
Mutlu F, Bozcuk S (2013) Tuzluluk Stresi Altında Büyütülen Ayçiçeği Bitkilerine Dışsal Uygulanan Poliaminlerin Yaprak Alanına Etkisi. Hacettepe Journal of Biology and Chemistry 41(4): 331-339.

Özel ÇA (2007) Onkogenik Agrobacterium tumefaciens A281 Hattı ile Çivit Otu (Isatis constricta Davis) Bitkisinde Tümör Oluşumu. Ankara Üniversitesi Ziraat Fakültesi Tarım Bilimleri Dergisi 13(4): 391-394.

Saleethong P, Sanitchon J, Kong-Ngern K, Theerakulpisut P (2013) Effects of exogenous spermidine (Spd) on yield, yield-related parameters and mineral composition of rice (Oryza sativa L. ssp. indica) grains under salt stres. Australian Journal Crop Science 7(9): 1293-1301.

Sales E, Kanhonou R, Baixauli C, Giner A, Cooke D, Gilbert K, Arrilaga I, Segura J, Ros R (2006) Sowing date, transplanting, plant density and nitrogen fertilization affect indigo production from Isatis species in a Mediterranean region of Spain. Industrial Crops and Products 23: 29-39.
Sgherri CLM, Maffei M, Navari-Izzo F (2000) Antioxidative Enzymes in Wheat Subjected to Increasing Water Deficit and Rewatering. Journal of Plant Physiology 157: 273-279.

Stoker KG, Cooke DT, Hill DJ (1998) Influence of light on natural indigo production from woad (Isatis tinctoria). Plant Growth Regulation 25: 181-185.

Uzunlu M (2006) Aspirinin Kavun Fidelerinin Değişik Abiyotik Stres Koşullarına Karşı Toleranslarının Artırılması Üzerine Etkileri. Yüksek Lisans Tezi, Kahramanmaraş Sütçü İmam Üniversitesi Fen Bilimleri Enstitüsü, Kahramanmaraş.

Verzera A, Condurso C, Dima G, Ziino M, Ragusa S (2010) Volatile Constituents in Dried Roots of Isatis tinctoria L. (Brassicaceae). Journal of Essential Oil Research 22(6): 483-485. 